Revista de Ciencias Sociales - Número 67 (2015) - Páginas 67-100

Conflictiva existencia entre el derecho social y el derecho tecnocrático

\title{
CONFLICTIVA EXISTENCIA ENTRE EL DERECHO SOCIAL Y EL DERECHO TECNOCRÁTICO
}

\author{
CONFLICT EXISTENCE \\ BETWEEN THE SOCIAL LAW AND \\ THE LAW TECHNOCRATIC
}

\author{
LEO DANIS TORRES BARRERO* \\ Universidad de Holguín (Cuba) \\ ltorrest@ict.uho.edu.cu \\ YUNIER RAMÍREZ CEDEÑO** \\ Universidad de Holguín (Cuba) \\ yramirezc@ict.uho.edu.cu \\ NUVIA ARTIGAS ALMARALES*** \\ Universidad de Holguín (Cuba) \\ nartigas@fh.uho.edu.cu
}

\section{Resumen}

El sujeto del discurso constitucionalista social antitecnocrático construye un concepto de libertad contra la alienación de los sujetos excluidos por el tecnocratismo. El discurso alternativo colectivista y de unidad disciplinar

* Profesor principal de Historia del Pensamiento Político y de Historia General del Estado y el Derecho. Artículo recibido el 11 de junio de 2015 y aceptado el 15 de noviembre de 2015 .

* $\quad$ Profesor asistente de Filosofía y Sociedad.

** Profesora principal de Historia de la Cultura Cubana.

Revista de Ciencias Sociales - Número 67 (2015) - Universidad de Valparáíso - ISSN 0716-7725-Valparaíso, Chile 
suscita reflexiones antropológicas, sociológicas, históricas, políticas y jurídicas contra la norma metódica de la razón tecnocrática. Por ello, proponemos explorar los presupuestos iusfilosóficos del liberalismo clásico de un lado y, de otro, el discurso político ancestral de las comunidades indígenas latinoamericanas, cuya imbricación sirve para que elucidemos las bases filosófico-antropológicas, filosófico-políticas y filosófico-jurídicas del constitucionalismo social antitecnocrático posible y deseado.

\section{Palabras claves}

Discurso constitucionalista social antitecnocrático, liberalismo, comunidades indígenas.

\section{Abstract}

The person of the social antitechnocratic constitutionalist discourse forges a freedom concept against the alienation of the excluded people by the technocratism. The alternative collectivist discourse and of disciplining unit provokes anthropological, sociological, historic, politic, and juridical reflections against the methodical norm of the technocratic reason. Hence, we propose exploring the iusphilosophic budgets of the classical liberalism in one side and, in the other, the ancestral political discourse of the Latin Americans indigenous communities, whose overlapping serves in order that we elucidate the philosophical- anthropological, philosophical-political and philosophicaljuridical bases of the possible and desired social antitechnocratic constitutionalism.

\section{Keywords}

Social antitechnocratic constitutionalist discourse, liberalism, indigenous communities.

\section{Introducción}

El tecnocratismo apuesta por una libertad individualista contra los atisbos colectivistas del liberalismo clásico. Esta relación contradictoria permite problematizar el discurso jurídico-político alternativo de tendencia colectivista, por ello proponemos examinar, brevemente, los presupuestos iusfilosóficos del liberalismo clásico de un lado y, de otro, el discurso político ancestral de las comunidades

Facultad de Derecho y Ciencias Sociales - Universidad de Valparaíso - Chile 
indígenas latinoamericanas, con el objetivo de imbricarlos y elucidar las bases filosófico-antropológicas, filosófico-políticas y filosóficojurídicas del constitucionalismo social antitecnocrático posible y deseado. La negación del pensamiento neoliberal tecnocrático de la categoría filosófica necesidad está precedida por la negación ideológica de las luchas por los derechos sociales y económicos. El tecnocratismo no da cuenta de que estos derechos son formas de expresión de la representación jurídica socialmente significativa para grandes sectores, incluyendo las propias clases liberales.

El discurso tecnocrático recobró nueva vitalidad en aparente lucha contra los totalitarismos y reivindicando aparentemente la democracia económica, cuando en verdad es una negación de los vislumbres colectivistas o comunitarios del liberalismo de los siglos XVIII y XIX, donde si bien se considera que el valor principal que debe tutelar las relaciones sociales es el mercado, su base filosófica e ideológica primaria no ignora aquellas previsiones colectivistas. De manera que el conflicto entre el ámbito económico y el político en el tecnocratismo globalizado y neoliberal se hace mucho más evidente que en el período premonopolista. El nacionalismo jurídicoconstitucionalista presupone su par contrario antinacionalista, el mismo que obstaculiza cualquier tendencia aun en el plano del nacionalreformismo. Los ideólogos del tecnocratismo jurídico, por su parte, buscan brizos de legitimidad social mediante pactos oligárquicos y el cierre a toda alternativa que rescate las mejores tradiciones del movimiento liberal.

El pensamiento constitucionalista antitecnocrático, se verá, es concebido como la posibilidad real de actividad desalienadora en circunstancias objetivas propicias con adecuada unidad disciplinar del conocimiento de las relaciones existentes entre los fenómenos, es un contenido básico que le permite al sujeto del discurso alternativo comprender la centralidad del hombre.

Tratándose del discurso alternativo, la cuestión del hombre es entonces de hecho la relación entre la verdad objetiva y la libertad humana. Cuando el sujeto excluido se dirige a un espacio organizado previamente por normas de paradigmas dominantes tecnocráticos que estructuran la práctica científico-tecnológica y las instituciones políticas,

Revista de Ciencias Sociales - Número 67 (2015) - Universidad de Valparáíso - ISSN 0716-7725-Valparaíso, Chile 
resignifica el concepto de hombre en la estructura argumentativa del discurso alternativo que construye, ante ese dominio tecnocrático. La verdad en Derecho es también una construcción del concepto hombre no al margen de los contextos prácticos de la acción humana.

El nivel antropológico, determinado a partir del análisis del discurso político comunitario indígena, permite una epistemología antiiuspositivista y antitecnocrática, porque reivindica la unidad de las ciencias ante la reducción positivista y trabaja al interior de cada ciencia particular y, en consecuencia, proyecta la centralidad desalienadora del hombre donde prevalece el orden que unifica el mundo de sus problemas concretos individuales (en correspondencia con un principio liberal clásico) y el mundo del concepto de libertad comunitaria. Es a partir de ahí que el sujeto del discurso alternativo construye su monismo metodológico y epistemológico.

\section{Derecho moderno vs derecho tecnocrático}

El Derecho moderno tiene su origen en los principios de la época de las luces. El Iluminismo fue una actitud de pensamiento radical en los albores de lo que después se dio en llamar Revolución Francesa. La razón se convirtió en el tribunal de todo lo existente. El enciclopedismo sostuvo la defensa del Derecho natural frente a la norma jurídica del poder monárquico. Se trataba de los derechos y libertades inalienables del hombre. Ya desde el siglo XVIII, en la Declaración de los derechos del hombre y del ciudadano proclamados por la Asamblea Nacional de Francia se expresaba que la realización de los derechos implica un respeto de lo individual. Así se plantea en su punto IV:

La libertad política consiste en poder hacer todo aquello que no cause perjuicio a los demás. El ejercicio de los derechos naturales de cada hombre, no tiene otros límites que aquellos necesarios para garantir a cualquier otro hombre el libre ejercicio de los mismos derechos; y estos límites sólo pueden ser determinados por la ley ${ }^{1}$.

1. "Declaración de los derechos del hombre y del ciudadano por la Asamblea Nacional de Francia”. En: Paine T.: Los derechos del hombre, Universidad Autónoma de Centro América, San José, 1986. Pág. 104.

Facultad de Derecho y Ciencias Sociales - Universidad de Valparaíso - Chile 
La facultad, entonces, que tiene cada hombre de posibilitar la convivencia pacífica en la sociedad mediante el respeto de los bienes de cada uno proviene de su capacidad de raciocinio libre. Todo individuo es un ser libre e igual a los demás por obedecer a los mismos dictados de la razón. Así, la eficacia de tales derechos no constituye una absolutización de lo individual y, no soslaya las consecuencias jurídicas de los mismos. Esta problemática es poco advertida por la historiografía del Estado y el Derecho.

Dicha estructura argumentativa del discurso iluminista elucida los contenidos que satisfacen la ideología de los liberales, es decir, el sujeto se reconoce así mismo como productor de ideas políticas libertarias histórica y ancestralmente fundamentadas. Es una toma de conciencia que parte del diálogo con los contextos conflictuales históricos y concretos. La libertad se presenta en el orden cosmovisivo individualista, sin embargo, presupone la necesidad insoslayable de romper las barreras de diferencias naturales. El tecnocratismo, por su parte, pone en entredicho que la libertad transcurra en un proceso tendente a lo colectivo, y que la igualdad jurídica elimine el hecho biológico de la diferencia.

El tecnocratismo constituye un movimiento homogeneizante, que se dispersa en disímiles esferas de la producción espiritual contemporánea. Su punto de partida esencial ha sido el mercado, pero no evade la teoría político-jurídica. Si según José María Mardones "la posmodernidad dice adiós al ideal moderno de la fundamentación y los grandes principios fijos, para abrirse a una nueva 'episteme' postmoderna de la indeterminación, la discontinuidad, el desplazamiento y el pluralismo"2, el tecnocratismo no es menos cierto que renuncia también a los grandes paradigmas modernos y preconiza el exceso de individualismo. La antinomia queda expresada cuando el derecho neoliberal erige el liberalismo como su base filosófica e ideológica primaria, y justifica, por consecuencia, el presupuesto de la libertad individual en las libres relaciones de la economía de mercado ignorando los atisbos colectivistas clásicos burgueses.

2. MARÍA MARDONES, José: ¿Qué es la posmodernidad? En: "Cuadernos de Orientación Familiar”, Alianza Universidad, Madrid (s/f). Págs. 39-40.

Revista de Ciencias Sociales - Número 67 (2015) - Universidad de Valparáíso - ISSN 0716-7725-Valparaíso, Chile 
Precisamente, uno de los teóricos cardinales del liberalismo del siglo XIX John Stuart Mill, declaraba en sintonía con los derechos de la comunidad que: "La única parte de la conducta de todo hombre de que es responsable ante la sociedad, es aquella que se relaciona con los demás. En lo que sólo concierne a él mismo, su independencia debe ser absoluta. Todo individuo es soberano sobre sí mismo, así como su cuerpo y su mente"3; es decir, la soberanía personal autónoma implica una responsabilidad jurídica de no afectación al otro, en este sentido dice Stuart Mill que "[...] el poder solo puede ejercerse con todo derecho contra la voluntad de cualquier miembro de una comunidad civilizada, cuando se trata de evitar daños a los demás”" . Esto concuerda con principios iluministas contractuales del siglo XVIII, en tanto que un individuo debe ser tratado como un rebelde al romper el compromiso de organización social, producto de la libertad originaria o natural ${ }^{5}$. El pensamiento de Stuart Mill, por su parte, plantea que la libertad económica presupone la libertad individual, la cual debe respetar el interés comunitario y el bienestar de cada individuo en particular.

El ideal constitucional republicano antitecnocrático que elucidamos es producto de la observación del desencadenamiento de la contradicción entre el pragmatismo jurídico de los ideólogos de la oligarquía neoliberal antinacional y la convergencia (influencia mutua, subordinación y exclusión, identificación y diferenciación) del liberalismo clásico con los presupuestos político-jurídicos comunitarios. Esta relación dialéctica estimula una problematización del discurso

3. STUART MILL, John: Sobre la libertad, Universidad Autónoma de Centro América, Costa Rica, 1965. Pág. 32.

4. Ídem.

5. De esta ideología liberal del pacto social, en la que el individuo es el valor supremo, se desprende una consecuencia política de mayor importancia con relación al nuevo orden social creado por la voluntad de los ciudadanos libres: por el pacto social los ciudadanos aceptan libremente sujetarse a las normas de igualdad y de restricción para crear y conservar el orden social. El ciudadano acepta también someterse a la ley que ha sido justamente creada por él para que le defienda y proteja este orden social. Al respecto véase a ROUSSEAU, Juan Jacobo: El contrato social, Editorial Taums, Madrid, 1966.

Facultad de Derecho y Ciencias Sociales - Universidad de Valparaíso - Chile 
alternativo de las comunidades indígenas; si bien una Constitución producto de la solución del conflicto a un nivel de desarrollo de dicha contradicción en el plano de las ideas no es patrimonio absoluto de semejantes comunidades, en este sentido, podemos aportar al debate teórico constitucionalista para proponer las bases filosóficoantropológicas, filosófico-políticas y filosófico-jurídicas de la Constitución social antitecnocrática posible.

\section{La legitimidad-legitimación antitecnocrática y el Estado Social de Derecho}

Los comentarios de Angelo Papachini sobre el tecnocratismo neoliberal son convenientes para un posterior análisis, a su juicio "los derechos sociales son cuestionados por los exponentes de la corriente neo-liberal con base en estos argumentos: a) carecen de justificación racional; b) presuponen de manera equivocada que el poder estatal tiene en sus manos la posibilidad de adecuar el orden del mercado a las necesidades de los miembros del cuerpo social; c) acaban por producir el efecto opuesto al que se proponen, porque obstaculizan el crecimiento armónico de la economía, que es el único instrumento eficaz para aumentar los recursos y disminuir la miseria; d) los fracasos o limitaciones con las que se enfrentan quienes reivindican los derechos sociales y económicos hacen que se difunda la convicción de que los derechos humanos, incluyendo los relativos a las libertades básicas, no son nada serio y que se reducen a mera retórica, a simple aspiración poética; e) las demandas ligadas con la satisfacción de necesidades abonan el terreno para el despotismo y el terror"'.

Detengámonos en refutar, por su orden de aparición, los argumentos neoliberales señalados con certeza por Papachini:

a) No es verdad que los derechos sociales "carecen de justificación racional”. Esto es una negación de los principios emancipatorios de la burguesía del siglo XVIII. El ideólogo constituyentista siempre le

6. PAPACCHINI, Angelo: Filosofía y derechos humanos, Universidad del Valle, Cali, 1994. Pág. 88.

Revista de Ciencias Sociales - Número 67 (2015) - Universidad de Valparáíso - ISSN 0716-7725-Valparaíso, Chile 
atribuye a uno o a varios elementos de la realidad el papel determinante y jerárquico para el orden republicano posible dentro de un contexto histórico-concreto. Los conceptos de soberanía, ciudadano, derecho, libertad, etc., aparecen en este ideólogo como un orden ontológico que construye a partir de la respuesta que le da a la problemática central en el campo del poder político: la interrelación individuo-sociedad-Estado. Actualmente los conceptos se debaten, en principio, entre una concepción individualista oligárquica y conservadora, que hiperboliza al individuo, es el caso del propio tecnocratismo neoliberal y una concepción que aglutina elementos individualistas y colectivistas del liberalismo de los siglos XVIII, XIX y el constitucionalismo social del siglo XX.

b) Ese tecnocratismo neoliberal niega la verdad histórica, al olvidar que a lo largo del XIX hasta la Segunda Guerra Mundial, los Estados occidentales sufren una transformación de radicalización y de corrección, pasan de Estados liberales (del laissez faire), a Estados sociales que supone el sistema de mercado regulado. Los derechos sociales están ligados a un contexto mundial caracterizado por la crisis espiritual que experimenta la cultura occidental, fenómenos que deben ser analizados en sus particularidades, pero que constituyen una unidad: la crisis mundial y los cambios en el pensamiento. Este último es de naturaleza teórica, pero con grandes implicaciones en la práctica constitucional. No es hasta principios del siglo XX que los derechos sociales, económicos y culturales van a ser regulados por los textos constitucionales ${ }^{7}$.

7. Tres hechos son paradigmáticos en este sentido: la Revolución de Octubre de 1917, y sus declaraciones de derechos sociales, económicos y culturales, la Constitución mexicana de 1917, primera en consagrar normativamente los derechos socioeconómicos y culturales y la Constitución de Weimar de 1919, Alemania, segundo texto constitucional que consagra estos derechos. En Estados Unidos la introducción de políticas de seguridad social se producen tras la crisis de 1929. La legislación social se conecta con la política del New Deal de Roosevelt. Se adoptan, en este país, medidas de asistencia social a desempleados y la intervención estatal en la economía para estimular la demanda. Por otra parte, la ley de relaciones de trabajo reconoce los derechos de sindicación y negociación colectiva.

Facultad de Derecho y Ciencias Sociales - Universidad de Valparaíso - Chile 
c) La realidad deplorable de muchos sectores de la sociedad latinoamericana indican los infortunios de las políticas neoliberales.

d) "Los fracasos" que mencionan los ideólogos tecnocráticos no se dan de forma gratis. La historicidad de la regulación de los derechos sociales y económicos indica lo intenso de la centralidad del conflicto social en el proceso de su concreción. La indisoluble unidad de pensamiento iusfilosófico e ideología política media necesariamente en la formación nacional donde el pacto nacional es el resultado de una intensa lucha de clases. Estos grupos no pueden soslayarse en el estudio del debate en torno a esos derechos. El problema nacional presume tendencias ideológicas oligárquicas y conservadoras sin las cuales no se comprende el papel progresista y nacionalista del lado opuesto. El pensamiento neoliberal no reconoce que La Ley suprema, en algunos países latinoamericanos que han emprendido un camino antineoliberal, no es atribuible exclusivamente a las fuerzas radicales, no es patrimonio absoluto de marxistas, indigenistas, ni de los liberales nacionalistas; es más bien un acto normativo construido por una racionalidad de la argumentación del discurso iusfilosófico indisoluble del fenómeno socioclasista, y estructura la positivización de los derechos fundamentales que violentan los criterios oligárquicos neoliberales iuspositivistas de naturaleza excluyente.

e) Es obvio que el tecnocratismo ignora, por razones ideológicas, que las necesidades sociales son objetivas y constantemente crecientes. El término necesidad se trata de una noción filosófica que designa la existencia de una contradicción en alguna circunstancia que de solucionarse se soluciona una necesidad social. Mientras, la necesidad esencial es el límite histórico-concreto de la actividad de los sujetos históricos, quienes han ido comprobando todas las posibilidades y le queda solo una: la imposibilidad del tecnocratismo de satisfacer las necesidades y reivindicación de las libertades clásicas en función de la colectividad, sin que esto obligue a renunciar a la individualidad.

La negación del pensamiento neoliberal de "las demandas ligadas con la satisfacción de necesidades" y la incomprensión de la categoría filosófica necesidad, arribas señaladas, desconocen que la plasmación de los derechos sociales y económicos en los textos constitucionales o

Revista de Ciencias Sociales - Número 67 (2015) - Universidad de Valparáíso - ISSN 0716-7725-Valparaíso, Chile 
en leyes complementarias, constituyen formas de expresión de la representación jurídica socialmente significativa lejos de "[abonar] el terreno para el despotismo y el terror". Los elementos normativos que informarían a la Constitución social antitecnocrática posible constituyen una solución y expresión de la diversidad que alcanza el ideal republicano en el momento de desencadenamiento de la contradicción entre el pragmatismo jurídico de los ideólogos de la oligarquía neoliberal antinacional y la convergencia (influencia mutua, subordinación y exclusión, identificación y diferenciación) del liberalismo clásico con los presupuestos político-jurídicos comunitarios.

El nacionalismo jurídico-constitucionalista presupone su par contario antinacionalista y a la vez lo supera. Los ideólogos del tecnocratismo jurídico están orquestados en el sentido de la conciliación engañosa, que busca brizos de legitimidad social, por ello quieren reformular constantemente pactos oligárquicos y cerrar el camino del nacionalismo liberal reformista.

La legitimidad-legitimación antineoliberal viabiliza al Estado Social de Derecho a través del sufragio universal, las elecciones periódicas y la acogida del pluralismo burgués. La profesora Emilia Bea es elocuente al respecto: "La legitimidad [...]; supone obediencia por referencia a algún valor comúnmente aceptado, que forma parte del consenso del grupo, sin necesidad del recurso a la fuerza, de una manera normalizada $[\ldots]$ ". . El constituyentista antitecnocrático y los sectores demandantes de transformaciones sociales a quienes representa son defensores de los principios democráticos; entre ellos el sufragio universal y el principio de legalidad enarbolada por la burguesía liberal de los siglos XVIII y XIX, y tiene como sustento el imperio de la ley.

La legalidad es fundamento de acto normativo, de ahí que los derechos pueden ser regulados por ley y diferentes actos normativos. El profesor Julio Fernández Bulté precisa que "[...] en esencia, el acto normativo en sentido estricto suele reducirse a la ley, técnica y exclusivamente entendida como norma legal de rango mayor, debajo de la Constitución y con fundamentación y formalidad que la colocan

8. BEA, Emilia: "Teorías de la justicia”. En: Introducción a la teoría del Derecho, Colectivo de autores, Editorial Félix Varela, La Habana, 2006. Pág. 368.

Facultad de Derecho y Ciencias Sociales - Universidad de Valparaíso - Chile 
por encima del resto de la normatividad jurídica de un país como cualquiera que esta sea" 9 , por tanto, una Constitución antitecnocrática podría vertebrar las bases del sistema político e institucional luego del periodo neoliberal. La ley es norma general emanada del órgano representativo, que deviene en regulación según principios racionales y sociales de la actividad estatal para garantizar el reconocimiento y defensa de los derechos y libertades fundamentales, lo que sí es "retórico" y "poético" es plantear que el Estado obstruye todo crecimiento económico desde esa perspectiva.

La Constitución antitecnocrática es resultado también de una aspiración de que no pierda su vigor por un acto de facto que transforme la estructuración jurídico-política del Estado. La administración debe comprender su sometimiento al principio de legalidad, la que exige el principio de la división de poderes y una cierta responsabilidad del ejecutivo ante el Congreso como órgano representativo de la voluntad popular. No puede admitirse prórroga de poderes, ni la enajenación del principio de debate parlamentario, porque el rejuego legislativo es un principio sostenido por el Estado liberal de Derecho, que previamente pasa por los filtros de los partidos electorales.

\section{El orden ontológico de libertad del indianismo}

\subsection{Diversidad, comunidad y reciprocidad}

Las culturas indígenas de América tienen niveles de conceptualización de las relaciones humanas que rigen sus comunidades. La dignificación del hombre constituye una norma moral orientada al dominio libre de sí mismo, y el conocimiento de la naturaleza a fin de desalienarlo. Esto demuestra que ellas tienen sus propias coyunturas cosmovisivas y ontológicas críticas, las cuales obligan al sujeto del discurso filosófico-antropológico alternativo a dialogar cercanamente y señalar la construcción del modelo de libertad que proyecta el discurso del indianismo.

9. FERNÁNDEZ BULTÉ, Julio: Teoría del Derecho, Editorial Félix Varela, La Habana, 2005. Pág. 240.

Revista de Ciencias Sociales - Número 67 (2015) - Universidad de Valparáíso - ISSN 0716-7725-Valparaíso, Chile 
Este discurso alternativo elucida el esquema normativoconceptual del indianismo para construir un orden ontológico de libertad que le sirva al sujeto alienado latinoamericano ${ }^{10}$. No impone una exigencia de racionalizar, instruir y normalizar a las culturas indígenas, sino que reivindica su pensamiento auténtico, donde emerge el interés porque el hombre sea fortaleza en todo orden natural y espiritual; no somete esta racionalidad al estricto logo occidental y más alcanza acuerdos universalmente aceptados sobre lo que debe entenderse por libertad, a partir de los aportes desalienadores del discurso del pensamiento de los pueblos indios en torno a las formulaciones cosmológicas y antropológicas.

En estas páginas abordaremos algunos de los discursos de las comunidades indígenas que constituyen paradigmas de los movimientos indígenas inclusive más recientes como en México, Bolivia, Ecuador y Brasil.

El 9 de abril de 2001, los aymara lanzaron un nuevo e histórico manifiesto que afirmaba:

Nosotros los aymara-qhichwas somos habitantes milenarios de este territorio llamado Qullasuyu, hemos nacido a la vida con raíces profundas en este continente americano, del vientre fecundo de nuestra Pachamama [...] Con mucho respeto y en armonía con la naturaleza nuestros ancestros han desarrollado nuestra propia filosofía de vida, nuestra ciencia y tecnología, nuestra espiritualidad. Durante milenios hemos sabido cultivar la vida en abundancia, sin explotar ni dañar a la naturaleza ni a nuestra comunidad ${ }^{11}$.

Se trata de un mononaturalismo dialéctico que constituye la base

10. A partir de este momento nos referiremos, en tercera persona, cuando hablemos del sujeto del discurso alternativo a los sectores excluidos por la racionalidad tecnocrática, ellos son: los propios indígenas, clases medias, campesinos, obreros, estudiantes y todo intelectual que comparta la idea de construir un pensamiento alternativo ante la avalancha hegemónica oligárquica que niega las conquistas del movimiento liberal revolucionario y nacional-reformista occidentales.

11. Acta de Reconstitución de la Nación Aymara-Qhichwa. Manifiesto de Jach'ak'achi, Bolivia. 2001. Disponible en www.puebloindio.org/Actualidades/ [Consultado: 20 de junio de 2014].

Facultad de Derecho y Ciencias Sociales - Universidad de Valparaíso - Chile 
del enfoque aymara-qhichwas antropologizado, según el cual existe una concatenación entre hombre, comunidad y naturaleza. El discurso filosófico-antropológico alternativo lo hace suyo porque insiste en una visión holística de la libertad concreta que favorece una aprehensión totalizadora.

El pueblo aymara-qhichwas se erige en sujeto del discurso político, y como tal, le atribuye a la unidad Pachamama-hombre el papel determinante o jerárquico para el orden posible. Posee un carácter cognitivo condicionado por el factor ideológico dentro del contexto conflictual histórico y concreto boliviano del momento. Hacen constar, en consecuencia, la existencia de la relación entre ideología, epistemología y política. El orden ontológico de la libertad es construido a partir de la concepción mononaturalista que tienen de esa relación.

El contenido de esa espiritualidad se opone al tecnocratismo dominante y a las ciencias hegemónicas. Los aymara-qhichwas no reducen el contenido de la razón a un lenguaje instrumental sobre datos fácticos. La filosofía de vida defendida resignifica la ciencia y la tecnología. La valoración pragmática de probabilidades técnicamente relevantes es sustituida por fines prácticos de preservación natural y humana. La ciencia y la tecnología aparecen totalmente subordinadas a la unidad Pachamama-hombre. Desde el punto de vista demográfico dicho manifiesto es relevante. Alrededor del 50 por ciento de la población boliviana es indígena, principalmente, quechuas y aymaras cuyos idiomas son considerados oficiales junto al idioma español.

La concepción de inferioridad natural de los indígenas pregonada por el eurocentrismo queda barrida ante la unidad Pachamama-hombre, lo que arremete contra el supuesto derecho a una sociedad superior sobre una inferior. El manifiesto advierte implícitamente la capacidad de los aymara-qhichwas de organizar la vida social según "raíces profundas" ancestrales y, sin imitación de los modelos excluyentes. Los aymara-qhichwas apuestan por un orden colectivo o comunitario.

El imperio de la razón metódica y el modo tecnológico de producción depredador también encuentra oposición en el movimiento indígena mexicano:

[...] indianismo podría llamarse a la fuerza organizativa y plural de organizaciones sociales indígenas, que buscan resolver los seculares problemas de tenencia de la tierra y obtener el reconocimiento legal,

Revista de Ciencias Sociales - Número 67 (2015) - Universidad de Valparáíso - ISSN 0716-7725-Valparaíso, Chile 
institucional y social a los derechos colectivos de los pueblos indígenas, como son la libre determinación, la autonomía indígena, los sistemas normativos propios, las formas de gobierno y de estructura social, la planeación y aplicación de recursos públicos, etc., todo ello a partir de investigación y acción autogestionaria $[\ldots]^{12}$.

Es a partir de ahí que el sujeto del discurso filosóficoantropológico alternativo puede construir y justificar su monismo metodológico y epistemológico (antropológico). El discurso político del indianismo unifica el mundo de los problemas concretos y el mundo del concepto de libertad, nada más afín a ese monismo. Esbozan la atmósfera ironista del individualismo neoliberal, a partir de la demanda de derechos en los contextos históricos, más cerca ahora de la crítica al Estado.

En su comprensión corriente, el conocimiento científico se encuentra atravesado por dos exigencias normativas: los requisitos de subordinación universal y de validación comunitaria, no ceñido al criterio de la coherencia lógica y la contrastación empírica del sujeto epistémico supuestamente neutral. La política aparece no como especulación sino búsqueda y ejercicio de derechos inalienables de los pueblos indígenas, por tanto, la libertad es práctica de derechos, y acción de la verdad en política. La idea "de investigación y acción autogestionaria” está reclamando una libertad en la vida social colectiva.

\subsubsection{Un diálogo con la antropología cultural}

Es difícil entender por qué el pensamiento filosófico-político alternativo en Latinoamérica ha prestado poca atención a la antropología cultural. En la antropología cultural temprana del norteamericano Alfred Louis Kroeber se indica la necesaria aprehensión de los valores culturales por parte del antropólogo y alerta inclusive a aquellos científicos de otras áreas de las ciencias sociales: "[...] ¿ cómo es posible, sin la más estéril incapacitación, hacer un estudio intelectual del hombre

12. Congreso Nacional Indígena. El Movimiento Nacional Indígena, México. 1997. Disponible en: www.laneta.apc.org/cni/mh-mni.htm [Consultado: 20 de junio de 2014].

Facultad de Derecho y Ciencias Sociales - Universidad de Valparaíso - Chile 
social que es el hombre cultural, y aun permanentemente no considerar su producto, cultural y la esencia de la cultura, sus formas y sus valores?" 13 .

Examinado con detalle, este presupuesto devela una concepción del modo de producción científica, la ciencia aquí se resiste a ser convertida en gestión de tecno-dirigentes y científicos eficaces y neutrales pretendidamente ajenos a las valoraciones y, al unísono, da cuenta del estado de presencia de la razón científica en la sociedad donde todo problema, público o privado, teórico o práctico, debe ser encarado valorativamente a pesar de las experimentaciones, mediciones y definiciones precisas del método de la física.

Más adelante señala Kroeber que su [...] enfoque acepta los valores como inherentes a la cultura y características de ella, así como parte de la naturaleza y, por tanto, susceptibles de estudio como cualquier otro grupo de fenómenos de la naturaleza, y de estudio por métodos análogos a los usados en el estudio de otras partes de la naturaleza, aunque necesariamente idénticos a la de la física [...]. De hecho, esto se ha hecho en todo estudio de la historia de un arte, en todo intento de presentar una religión, en todas las consideraciones etnográficas que surgen por encima de la especificación mecánica, en todos los escritos sobre la historia de la cultura que son más que atomísticos ${ }^{14}$.

El legado antropológico de Kroeber muestra la justificación de una instancia reflexiva interior y ulterior a la investigación científica que puede ser utilizado constitucionalmente contra el cientificismo y tecnocratismo alienadores actuales. El sujeto del discurso filosóficoalternativo se plantea epistemológica y axiológicamente, la construcción de la ciencia, como momento de la realidad cultural; pues la ciencia no debe reducirse a puro ejercicio metódico "[...] la cultura sólo puede existir cuando existe una sociedad; y a la inversa, cada sociedad humana va acompañada por una cultura" ${ }^{15}$. La estructura argumentativa del

13. KROEBER, Alfred Louis: "El concepto de cultura en la ciencia". En: Bohannan, Paul y Glazer, Mark (compiladores): Antropología. Lecturas, Segunda edición, Editorial Félix Varela, La Habana, 2005. Pág. 114.
14. Ibíd. Pág. 115.
15. Ibíd. Pág. 105.

Revista de Ciencias Sociales - Número 67 (2015) - Universidad de Valparáiso - ISSN 0716-7725-Valparáís, Chile 
discurso alternativo resignifica estos conceptos antropológicos frente al sujeto dominante.

La cuestión del hombre es para el discurso filosóficoantropológico alternativo la relación entre la verdad objetiva y la libertad humana. La comprensión de esta relación hace suya asimismo, el fundamento antropológico de Kroeber, cuando plantea que en "el pasado ha sido un problema que los valores se considerasen productos directos de la deidad, que estaba fuera y por encima de la naturaleza, o emanaciones del alma [...]. Pero, con seguridad, esos días han acabado $[\ldots]]^{\prime 16}$, para permitirle comprender al sujeto del discurso alternativo que la práctica religiosa del sujeto excluido se presenta como una ideología que invierte la realidad.

Este antropólogo pone el acento en el método para explicar los valores culturales, puesto que su preocupación principal es el conjunto de reglas que validan al conocimiento científico, diferenciándolo de la creencia, la opinión y el mito. Lo significativo está dado, aunque no se comparta del todo la identidad del método con la física en el estudio de los fenómenos sociales, en la segunda pregunta y la seguida reflexión que elabora sobre los valores:

Es verdad que se suelen relegar muchos de estos estudios a las llamadas "humanidades" y, con ello, se excluyen de las llamadas "ciencias sociales". Pero, ¿qué ocurre con ello siempre y cuando los fenómenos en cuestión y sus fuerzas naturales se consideran como parte del resto de la naturaleza y, en ningún caso en sentido sobrenatural? Y también siempre que estén sujetos a disección, recombinación y deducción según las reglas básicas de evidencia seguidas en la investigación de otras partes o esferas de la naturaleza, sin entrada de tendencias, ventaja personal, autosuperioridad o etnocentricidad ${ }^{17}$.

Decididamente, Kroeber incrimina las posiciones que creen en la superioridad étnica y la consecuente justificación de su expansión eterna. Los antropólogos Paul Bohannan y Mark Glazer afirman que Kroeber “[...] usó la idea — se refieren a los superorgánicos de Spencer-

16. Ibíd. Pág. 115.

17. Ídem.

Facultad de Derecho y Ciencias Sociales - Universidad de Valparaíso - Chile 
para explicar algo sobre la cultura [...]"18, se entiende no en el sentido socialdarwinista que justificó la colonización imperialista. El discurso filosófico-antropológico alternativo rechaza la etnocentricidad y se remonta a aceptar la colectividad defendida por las comunidades indígenas.

Entre los discursos más representativos y de plena vigencia de los pueblos indígenas al respecto está el de Ollantaytambo, de 1980, Cuzco, en ocasión de la fundación del Consejo Indio Sudamericano (CISA):

Que el pensamiento cósmico de la vida y del mundo que nos rodea, es la base sustantiva para comprender la IDEOLOGÍA INDIANISTA, la cual significa: orden en constante movimiento y la armónica sucesión de opuestos que se complementan. Que, la IDEOLOGÍA INDIANISTA como el pensamiento del mismo Indio, de la naturaleza y del universo, es la búsqueda, el reencuentro y la identificación con nuestro glorioso pasado, como base para tomar en nuestras manos la decisión del destino de los pueblos indios; Que, el INDIANISMO se nutre en la concepción colectivista y comunitarista de nuestra civilización tawantinsuyana, basada en la filosofía del bienestar igualitario; Que la concepción científica india, define al hombre como parte integrante del cosmos y como factor de equilibrio entre la naturaleza y el universo, ya que de ello depende el desarrollo de su vida creadora en la tierra ${ }^{19}$.

La libertad se presenta en el orden cosmovisivo colectivista, aunque no aparezca textualmente presupone la necesidad insoslayable de romper las barreras coloniales y neocoloniales. Estos pueblos aspiran revalidar su historia, lengua, costumbres, etc., frente a los patrones externos que exaltan el individualismo.

El discurso alternativo se acerca a la indisoluble imbricación del regocijo de la identidad cultural con el ejercicio de la autodeterminación comunitaria que proclaman los pueblos indios ante el mundo unipolar

18. BOHANNAN, Paul y GLAZER, Mark (compiladores): Antropología. Lecturas, Ob. Cit. Pág. 103.

19. Estatutos, Consejo Indio Sudamericano (CISA), Cuzco, Perú, 1980. Disponible en www.puebloindio.org/CISA/cisa.htm [Consulta: 20 de junio de 2014].

Revista de Ciencias Sociales - Número 67 (2015) - Universidad de Valparáíso - ISSN 0716-7725-Valparaíso, Chile 
y globalizado. La ideología indianista llana el camino de la desalienación y justifica la resignificación teleológica y epistémica del concepto alternativo de libertad en sintonía con la igualdad frente al concepto de libertad empírico-descriptivo, tecnocrático y hegemónico. El interés es mayor si se tiene presente que en el propio Perú, base de esa proclamación sudamericana, alrededor del 45 por ciento de su población es indígena, muchos de los cuales son descendientes de los incas.

El discurso filosófico-antropológico alternativo, en este caso, entiende que la antropología cultural debe penetrar las particularidades expresadas en dicho discurso indígena para orientar en el intento de comprender la historia no sólo de estos pueblos, a través de la descripción, clasificación y tipologización de las formas diversas de organización de la vida cultural, sino de la humanidad como un proceso único, interrelacionado y ascendente.

La Declaración de Quito, la voz del movimiento indio ecuatoriano, representa a 120 naciones, tribus y organizaciones indígenas de 20 países de América. Emblemáticamente anuncia que el encuentro de 1990 representa la conciencia de siglos de resistencia:

[...] nuestra concepción de la tierra está sustentada por la comprensión de que lo humano y lo natural es similar y a la vez está interrelacionado. Nuestras formas políticas, económicas y productivas, todas son formas culturales y están enraizadas y orientadas por el comunitarismo. Además, creemos que la propiedad de la tierra es colectiva. Cultivamos en comunidad y distribuimos los frutos en comunidad. Y además creemos en la solidaridad, nuestros niños son de la comunidad $[\ldots]^{20}$.

Asumir a los pueblos indígenas como una identidad diferenciada desde el antietnocentrismo desalienador y a la vez de integración comunitaria le permite al sujeto del discurso filosófico-antropológico alternativo incorporar los posibles resultados investigativos de la antropología, por ejemplo, las relaciones de parentesco o de descendencia entre grupos e individuos y su incidencia en las normas específicas que regulan los medios de producción y las formas de

20. Disponible en www.nativeweb.org/papers/statements/quincentennial/ quito.php [Consultado: 20 de junio de 2014].

Facultad de Derecho y Ciencias Sociales - Universidad de Valparaíso - Chile 
distribución de la tierra y los productos del trabajo y los símbolos del lenguaje. Solo así el sujeto del discurso alternativo comprende en lo más profundo los reclamos de este grupo de indígenas en torno al derecho a la autonomía y al autogobierno dentro de los países donde viven.

El comunitarismo indígena insta al Estado-nación a reconocer sus formas políticas, económicas y productivas, por tanto, la necesidad de un Derecho comunitario sale a flote. En todo caso, pudieran subsistir dos sistemas jurídicos o la confluencia de dos legislaciones en un mismo sistema jurídico.

El discurso filosófico-antropológico alternativo defiende la particularización del derecho positivo y señala las insuficiencias teóricas del positivismo jurídico y el normativismo que le es consustancial. El discurso político de las comunidades indígenas lleva implícito dicha crítica desde un fundamento cultural que unifica hombre, ciencia y naturaleza. La teoría constitucional y la Ciencia del Derecho deberían acercarse sin prejuicios al antropólogo evolucionista Julian Steward, quien advierte que la estructura interna de una familia conlleva reglas sociales que condicionan las formas de matrimonio, de filiación y de residencia que legitiman el nacimiento de esta familia. Señala, además, que determinan algunos aspectos de su desarrollo. El indígena se autorreconoce parte de un grupo, no es casual planteen que sus "niños son de la comunidad"21.

El discurso filosófico-antropológico alternativo apuesta por el reconocimiento de la identidad diferenciada desde el antietnocentrismo alienador y por el respeto a la integración comunitaria indígena tan demandada, sin obviar las contradicciones elucidadas por el antropólogo norteamericano Clifford Geertz, el cual llama la atención sobre las problemáticas y desafíos de la diversidad en cuanto a los usos, costumbres, símbolos y lenguajes enfrentados dentro de una misma sociedad:

21. Al respecto véase a STEWARD, Julian: "Niveles de integración sociocultural: un concepto operativo". En: Southwestern Journal of Anthropology, nro. VII, 1951. Págs. 374-390.

Revista de Ciencias Sociales - Número 67 (2015) - Universidad de Valparáíso - ISSN 0716-7725-Valparáiso, Chile 
Más concretamente, las cuestiones morales suscitadas por la diversidad cultural (que están, por supuesto, lejos de ser todas las cuestiones morales que existen) que, de surgir, lo hacían principalmente entre sociedades — las «costumbres contrarias a la razón y la moral», ejemplo de tema de que se nutrió el imperialismo—- surgen ahora cada vez más dentro de ellas mismas ${ }^{22}$.

Del problema conflictual entre sociedades se ha pasado (sin que este haya desaparecido) al problema del conflicto intrasocietal antes de menor envergadura, pero ha tomado "[...] proporciones extremas y casi universales $[\ldots]$ "23, uno de los mayores "desafíos morales a los que hoy nos enfrentamos" ${ }^{24}$. En el siglo XX, ya avanzada su segunda mitad, Clifford Geertz certificó que:

La famosa absorción antropológica con lo exótico, los jinetes beréberes, los vendedores ambulantes judíos, los legionarios franceses, es esencialmente un truco para desplazar el sentido negativo de la familiaridad con el que se esconde el misterio de nuestra propia habilidad para relacionarnos perceptivamente uno con otro [...]. Comprender la cultura de un pueblo expone su normalidad sin reducir su particularidad. Cuanto más entiendo lo que hacen los marroquíes, más lógicos y singulares me parecen. Esto les hace accesibles: estableciéndolos en la estructura de sus propias habilidades, disuelve su opacidad ${ }^{25}$.

Se refiere a lo particular de una comunidad dentro de la sociedad. Geertz enfrenta a los discursos con pretensión de universalidad que ocultan la diversidad. La particularidad presupone la diversidad y la universalidad necesarias. La cultura científica antropológica deviene

22. GEERTZ, Clifford: Los usos de la diversidad, Editorial Paidós, Barcelona, España, 1996. Págs. 81-82.

23. Ibíd. Pág. 90.

24. Ídem.

25. GEERTZ, Clifford: "Descripción densa: hacia una teoría interpretativa de la cultura”. En: Bohannan, Paul y Glazer, Mark (compiladores): Antropología. Lecturas, Ob. Cit. Pág. 555.

Facultad de Derecho y Ciencias Sociales - Universidad de Valparaíso - Chile 
en método específico de resolución racional de problemas, le da contenidos a la cultura discursiva desalienadora y desarrolla la racionalización de las actividades sociales de todo orden, entre ellas la comunicativa. Estructurado el discurso filosófico-antropológico alternativo en torno a los flujos de semejante información que no ignora la interrelación particular-universal puede garantizar que el hombre sepa qué hacer en estas sociedades con la abrumadora capacidad de información.

Ese autor desea un gesto político de profundas raíces antropológicas:

Necesitamos una nueva variedad de política, una política que no contemple la afirmación étnica, religiosa, racial, lingüística o regional como un resto irracional, arcaico y congénito que ha de ser suprimido o trascendido, una locura menospreciada o una oscuridad ignorada, sino que, como ante cualquier otro problema social-digamos la desigualdad o abuso de poder, lo vea como una realidad que ha de ser abordada, tratada de algún modo, modulada; en fin, acordada ${ }^{26}$.

El antropólogo mexicano Héctor Díaz Polanco define la diversidad como:

[...] la coexistencia de sistemas culturales distintos. Pero también puede comprenderse como la necesaria convivencia de varios enfoques doctrinales de carácter comprensivo (filosóficos, religiosos, políticos, etc.) que permiten a los individuos construir (no obstante pertenecer a un mismo sistema cultural [...] distintas visiones del mundo, de los fines de la existencia y concepciones de lo que para cada uno de ellos constituye la 'vida buena' [...]. Sin embargo, reconocer que existen diferentes creencias, ideales o puntos de vista personales, que es a lo que presta atención las variantes liberales que se autoproclaman 'pluralistas', aun dejan de lado el núcleo central y relevante de la diversidad ${ }^{27}$.

26. GEERTZ, Clifford: Reflexiones antropológicas sobre temas filosóficos, Editorial Paidós, Barcelona, España, 2002. Pág. 248.

27. DÍAZ POLANCO, Héctor: Elogio de la diversidad. Globalización, multiculturalismo y etnofagia, Fondo Editorial Casa de las Américas, La Habana, Cuba, 2008. Pág. 27.

Revista de Ciencias Sociales - Número 67 (2015) - Universidad de Valparáíso - ISSN 0716-7725-Valparáiso, Chile 
Es una definición que no admite el rechazo a la diversidad que tiende a la creación de normativas epistemológicas y metodológicas deterministas, naturalistas y socialdarwinistas. La investigación objetivista, toma al hombre como objeto, que debe ser descrito y explicado a fin de controlarlo; reduce la realidad social a hechos descontextualizados; toda una racionalidad instrumental con pretensiones de neutralidad valorativa. Ese paradigma pluralista queda desacreditado ante el discurso filosófico-antropológico alternativo, el cual se apodera del concepto de diversidad arriba señalado.

La categoría central de este discurso alternativo no es de carácter estrictamente lógico-metodológico a la manera de la verificación o falsación positivista, sino filosófico-antropológico. La diversidad debe ser considerada una categoría filosófico-antropológica de carácter transdisciplinaria, que remita a una comunidad de hombres, no a una comunidad científica supuestamente neutral. La ruptura alternativa tiene una lógica de centralidad del hombre contra la circularidad paradigma pluralista-neutralidad científica.

El monismo metodológico y epistemológico antropológico conduce a un ideal de ciencia que busca leyes y elabora un saber que tributa al proyecto de entendimiento y preservación del orden de la diversidad cultural y no al control de prácticas diferentes.

El antropólogo Julio Tereucán destaca que la reciprocidad es el [...] intercambio normado de bienes y/o servicios en un determinado contexto cultural, que involucra a conjuntos de individuos o grupos domésticos bajo una categoría de eventos de intercambio, y donde se une la solidaridad económica, el afianzamiento de una relación social entre las partes y los niveles de inclusión de los grupos domésticos en la dinámica social y cultural de una comunidad ${ }^{28}$.

En otro trabajo este autor precisa que la reciprocidad abordada desde $[. .$.$] la teoría antropológica social posee interés por dos razones$ fundamentales: una, porque puede proporcionar una estrategia metodológica de gran capacidad explicativa e interpretativa y, otra,

28. TEREUCÁN, Julio: Redes de reciprocidad e intercambio y su influencia en la cultura y economía de una comunidad postnahua de México, Tesis de Maestría, Universidad Iberoamericana de México, México, 2003.

Facultad de Derecho y Ciencias Sociales - Universidad de Valparaíso - Chile 
porque permite acceder a ciertas implicaciones de tipo ético, moral e ideológico presentes en la reciprocidad, así como a las formas materiales de organización y regulación de la vida social humana ${ }^{29}$.

Hay cierta articulación estructural entre los individuos que conforman una comunidad y, por lo tanto, el sujeto del discurso filosófico-antropológico como observador puede describir una conducta recíproca entre ellos. Pero lo alternativo del discurso tendrá necesariamente que acudir al concepto antropológico de reciprocidad. Esta está formada por la coordinación de individuos con al menos mínima autonomía. La comunidad no restringe la libertad creativa individual, pues esta existe para ella; la coherencia en las relaciones e interacciones entre sus miembros o entre comunidades se deben a factores económicos, de costumbres, normas de conductas, cuestiones gnoseológicas, religiosas, etc., y posibilitan el crecimiento en ella. Esto permite un imperecedero aprendizaje social que su propia trama lingüística define.

En las comunidades mapuches de Chile, por ejemplo, existe la reciprocidad en tres ámbitos: en el interior de la familia, entre vecinos y en el ámbito comunitario. Pueden mencionarse las relaciones económicas entre campesinos, actividades de subsistencia social y cultural de los grupos domésticos, aprendizaje de los códigos de ayuda, condescendencia de los padres para con sus hijos casados, los cuales reciben recursos que les facilita ahorrar de forma independiente, vínculos entre comunidades por razón del matrimonio, en este sentido, remuneraciones y retribuciones de bienes a la familia de la novia, determinadas formas de trabajo comunitario en beneficio de toda la comunidad o de alguna familia que no pueda hacerlo por sí misma.

La reciprocidad funciona como mecanismo de control de conductas asimiladas por los miembros de la comunidad. Estos aprenden e interpretan normas de ejercicio comunitario que constituyen

29. TEREUCÁN, Julio y CARO PUENTES, Aracely: "La reciprocidad como mecanismo de control social en los contextos familiares indígenas: los mapuches del sur de Chile”. En: Vera, Ana y Robichaux, David (compiladores): Familias y culturas en el espacio latinoamericano, Universidad Iberoamericana-Centro de Investigación y Desarrollo de la Cultura Cubana Juan Marinello, México, 2008. Pág. 279.

Revista de Ciencias Sociales - Número 67 (2015) - Universidad de Valparáíso - ISSN 0716-7725-Valparaíso, Chile 
aspectos simbólicos trasferibles a todos e integran parte de su cosmovisión. Pensar la reciprocidad desde un punto de vista indígena puede ser una alternativa para entender las interrelaciones comunitarias que generan sentimientos de identificación y pertenencia socialmente aceptados, porque son propios del modelo cultural donde los individuos aprenden e interpretan las normas de convivencia no impuestas externamente por sujeto dominante alguno. La solución de la problemática de interrelación individuo-comunidad es esencialmente colectivista. Llama la atención la función recíproca y de convivencia del respeto intrafamiliar, por ejemplo en los nahuas de la Sierra Norte de Puebla.

El antropólogo James Taggart dice al respecto:

[...] inculcar icnoliz (respeto) tiene el fin sobre todo de mantener buenas relaciones entre hermanos [...] La unidad fraternal es muy importante en el grupo doméstico donde los hermanos deben trabajar juntos - ce cosa tequitih - con sus padres para llenar el granero y la bolsa familiar. A pesar de que los hermanos a veces se pelean y se dividen durante el ciclo de desarrollo del grupo doméstico, el icnoliz sirve como guía para el comportamiento preferido en la familia nahuat ${ }^{30}$.

La lógica de centralidad del hombre en el discurso filosóficoantropológico tiene un fundamento cultural que unifica hombre, comunidad, conocimiento y naturaleza. Este discurso asume desde el antietnocentrismo desalienador a los pueblos indígenas como una identidad diferenciada de integración comunitaria. El sujeto del discurso alternativo sistematiza o resignifica conceptos técnicos y científicos de la comunidad científica antropológica y las formulaciones cosmológicas y cosmovisivas de las comunidades indígenas y sus funciones. La estructuración argumentativa del discurso alternativo expresa un orden

30. TAGGART, James M.: "Cómo los niños nahuas aprenden a ser adultos: inculcando el respeto hoy en día en una comunidad mexicana”, III Reunión del Grupo de Trabajo Familia e Infancia, Consejo Latinoamericano de Ciencias Sociales (CLACSO), Valdivia, Chile, 29 de septiembre al 1 de octubre de 2003. Pág. 8; citado por LORENTE FERNÁNDEZ, David: "La transmisión intergeneracional del conocimiento mítico a través de la tradición oral: los ahuaques o espíritus del agua en la Sierra de Texcoco, México”. En: Vera Estrada, Ana y Robichaux, David (compiladores): Familias y Culturas en el espacio latinoamericano. Pág. 301.

Facultad de Derecho y Ciencias Sociales - Universidad de Valparaíso - Chile 
de expresiones desalienadoras, como son la diversidad, comunidad, reciprocidad, entre otras.

El carácter individualista neoliberal no está presente en el constructo ontológico de libertad comunitaria de los indígenas. Resulta interesante, en tal sentido, la explicación siguiente sobre la comunidad mapuche del sur de Chile:

La reciprocidad también se manifiesta tácitamente en las ceremonias religiosas como lo es el nguillatun, expresándose a través de la rogativa en agradecimiento a Chao ngenechen por los favores concedidos o para pedir por buenas cosechas, entre otros objetivos. Pero en ello el significado de la reciprocidad está latente y el no ejecutarla implica una sanción divina. Por lo que expresiones como «hay que respetar la cultura, así Chao Genechen nos protege y el Miche Mapu viene con sus wekufesa hacernos daño» simbolizan que toda acción no devuelta involucra una repercusión negativa ${ }^{31}$.

La religión y el mito viabilizan fines prácticos de preservación natural, humana y de reciprocidad. Poseen un carácter cognitivo condicionado por el factor ideológico dentro del contexto conflictual concreto de las comunidades indígenas, condicionante de requisitos de subordinación universal y de sanción comunitaria, no ajustado a los criterios de la coherencia lógica y verificación utilitarista del sujeto dominante.

Hoy, esa construcción cosmovisiva y ontológica que pone en el centro al hombre, transmite una alerta para discutir y solventar cuestiones acerca de la producción y distribución del conocimiento en la sociedad. Estas son cuestiones que acontecen en la vida social pero que embarazosamente aciertan un espacio democrático para su discusión. Una forma de expresarlo concisamente es decir que la antropología social constituye además una reflexión axiológica del conocimiento producido en las comunidades humanas.

El punto de partida del antropólogo inglés Edward B. Tylor es la definición clásica de cultura como totalidad compleja. Ahora bien, este

31. TEREUCÁN, Julio, CARO PUENTES, Aracely y KETTERER, Lucy: "La reciprocidad como mecanismo de control social en los contextos familiares indígenas: los mapuches del sur de Chile”. En: Vera, Ana y Robichaux, David (compiladores): Familias y culturas en el espacio latinoamericano. Pág. 290.

Revista de Ciencias Sociales - Número 67 (2015) - Universidad de Valparaíso - ISSN 0716-7725-Valparaíso, Chile 
trabajo ha accedido a través de él a una visión desprejuiciada de la religión:

[...] Pocos de los que entreguen sus mentes a dominar los principios generales de la religión salvaje nunca volverán a considerarla ridículo o su conocimiento superfluo para el resto de la humanidad. Lejos de que sus creencias y prácticas sean un montón de disparates, son consistentes y lógicas en un grado tan alto como para empezar [...] a exponer los principios de su formación y desarrollo; y estos principios prueban ser esencialmente racionales, a pesar de trabajar en una condición mental de intensa e invertebrada ignorancia ${ }^{32}$.

Allí está presente el discurso alternativo y vuelve sobre su propio recorrido cuando comprende que la vida espiritual de las comunidades indígenas está sometida a condicionamientos, en última instancia, de producción y reproducción de su vida material, y que sus autores no tienen conocimiento profundo de ello. Un monismo que unifica la verdad objetiva, el mundo de los símbolos y los problemas concretos del hombre. Por tanto, el sujeto del discurso alternativo resignifica imágenes, símbolos (rituales y no rituales) y la cosmovisión indígenas no para imponer estas prácticas a las otras sociedades, sino para desenmascarar la inversión de la realidad del sujeto dominante. Es posible, entonces, construir una filosofía antropológica interrogando y observando a los individuos e interpretando significados propios de las relaciones comunitarias, razón por la cual es posible proponerse un monismo metodológico y epistemológico antropológico que sirva a los fines de una práctica social libertaria.

La libertad, en todas sus manifestaciones política, económica, religiosa, jurídica etc., es concebida como la posibilidad real de actividad desalienadora en circunstancias objetivas propicias con adecuada unidad disciplinar del conocimiento de las relaciones existentes entre los fenómenos, es un contenido básico que le permite al sujeto del discurso filosófico-antropológico alternativo comprender la centralidad del hombre. Tratándose del discurso filosófico-antropológico alternativo, la cuestión del hombre es entonces de hecho la relación entre la verdad objetiva y la libertad humana.

32. TYLOR, Edward B.: "Cultura Primitiva”. En: Bohannan, Paul y Glazer, Mark (compiladores): Antropología. Lecturas. Pág. 77.

Facultad de Derecho y Ciencias Sociales - Universidad de Valparaíso - Chile 
Cuando el sujeto se dirige a un espacio organizado previamente por normas de paradigmas dominantes que estructuran la práctica científico-tecnológica y las instituciones políticas, resignifica en la estructura argumentativa del discurso alternativo, el concepto de hombre ante el dominio tecnocrático. La verdad en política es también una construcción del concepto hombre no al margen de los contextos prácticos de la acción humana.

El discurso filosófico-antropológico alternativo al unificar el mundo de los símbolos y de los problemas concretos del hombre afirma el significado étnico, religioso, racial, lingüístico y regional de las comunidades indígenas. El desentrañamiento de las estructuras de significación de la cultura es una dimensión epistemológica de reconocimiento de las comunidades humanas en su diversidad étnica, lingüística, religiosa, etc.

El movimiento de la ciencia antropológica es precisamente ese movimiento de las "[...] estructuras conceptuales complejas $[\ldots]$ extrañas, irregulares, no explícitas, y a las cuales el etnógrafo debe ingeniarse de alguna manera, para captarlas primero y explicarlas después $[\ldots]]^{\prime 33}$. Geertz unifica este presupuesto metodológico con el gesto político antes aludido. Sobre el particular, el antropólogo cubano Ramfis Ayús esclarece que "la descripción densa implica entonces preocuparse menos por un enfoque causalista y legal de la cultura y más por su condición de redes de sentido y significación: la cultura como cruces de lenguajes, la lengua y los lenguajes como códigos culturales que determinan (estructuran) prácticas y decisiones" ${ }^{34}$.

\subsection{Símbolo, mito y libertad}

Ernst Cassirer en su voluminoso tratado Filosofía de las formas simbólicas, de 1925, alegaba que el hombre es un animal simbólico,

33. GEERTZ, Clifford: La interpretación de las culturas, Editorial Gedisa, Barcelona, España, 1992. Pág. 24.

34. AYÚS REYES, Ramfis: "El juego de Geertz o la densidad cultural”. En: $L a$ aventura antropológica. Cultura, poder, economía y lenguaje, Editorial de Ciencias Sociales, La Habana, 2007. Pág. 13.

Revista de Ciencias Sociales - Número 67 (2015) - Universidad de Valparáíso - ISSN 0716-7725-Valparáiso, Chile 
porque lo engloba un constructo universal de lenguaje, arte, mito y religión. El símbolo desplaza la concepción de hombre como animal racional por el hombre como animal simbólico. El símbolo sustituye el imperio de la razón, aunque la presupone. Occidente se vuelve hacia sí misma y rectifica el exceso de confianza en la explicación de la racionalidad científica, tecnológica e inclusive cristiana de todo cuanto existe. El símbolo se erige contra el logos homogeneizante, en este sentido, es una categoría heterogénea y desalienadora que expresa la diversidad cultural.

Adolfo Columbres, jurista, filósofo y antropólogo argentino, sostiene que en el pensamiento de Cassirer hay una perspectiva antropológica, esto es, [...] la particularidad histórica de las redes simbólicas. La universalidad de los símbolos no puede ser interpretada como que todos los hombres participan de una misma simbología, lo que podría ser la aspiración del cosmopolitismo más extremo. Cada sociedad teje su propia red, la que viene a ser su cultura, razón por la cual el concepto de matriz simbólica se usa casi como sinónimo del de matriz cultural ${ }^{35}$.

Desde ya, la imbricación entre la reciprocidad indígena y el símbolo debe ser vista como una matriz práctica que desarrolla al imaginario de las comunidades. Marcel Mauss ${ }^{36}$ enfatiza que el regalo y el don materializan la reciprocidad y simbolizan la disposición del individuo a relacionarse socialmente, a la vez que generan obligaciones retributivas para el receptor, moralmente sancionadas si este incumple. La acción de reciprocidad de las comunidades indígenas, por ejemplo de los mapuches de Chile, se caracteriza además, por la persistencia del rito y las ceremonias religiosas como lo es el nguillatun, de agradecimiento o petición a Chao Genechen por los favores concedidos o para pedir buenas cosechas, simboliza que todo trasgresión de las obligaciones recíprocas contraen sanciones y repercusiones negativas.

35. COLOMBRES, Adolfo: "El mito como zona sagrada. El pensamiento simbólico". En: Teoría transcultural de las artes visuales, Ediciones ICAIC, La Habana, 2011. Pág. 26.

36. MAUSS, Marcel: "Ensayo sobre los dones. Motivo y forma de cambio en las sociedades primitivas”. En: Sociología y antropología, Editorial Tecnos, Madrid, 1971.

Facultad de Derecho y Ciencias Sociales - Universidad de Valparaíso - Chile 
La acción de reciprocidad adquiere su significado en lo simbólico, también, en los remedios del bosque y en el teñido. La machi mapuche, persona habitualmente mujer, es la que se ocupa fundamentalmente de curar los enfermos, se debe dar al bosque algo a cambio; si se saca añil de una canal para teñir lana, se debe pedir permiso y dar algo a cambio. El no cumplimiento de ello implicará la negativa natural de curar los enfermos, el mal teñido de la lana o algún accidente o enfermedad.

No viene al caso hacer un análisis exhaustivo de cada una de las comunidades indígenas. La idea esencial que queremos transmitir es que en ellas no cabe el cosmopolitismo tecnocrático neoliberal dominante. El diálogo con la antropología filosófica de Cassirer es presupuesto reivindicador del pensamiento simbólico. Cada unidad semántica adjudicada por las comunidades indígenas a los objetos y el orden jerárquico de los significados derivados son concretos simbólicos socialmente compartidos. La defensa del concreto simbólico es la defensa de la diversidad misma.

Existe un consenso intelectual, ciertamente con matices epistemológicos diferenciados, en torno al reconocimiento del universo simbólico; pero no siempre impregnados de gestos políticos contrahegemónicos. En otras palabras, el monismo metodológico y epistemológico antropológico alternativo unifica la antropología filosófica de Cassirer y el desentrañamiento de las estructuras de significación de la cultura que exige Geertz, y reafirma de tal forma el reconocimiento de la diversidad étnica, lingüística y religiosa de las comunidades humanas. La diversidad presupone la particularidad del concreto simbólico y la universalidad del símbolo. La diversidad se ratifica como una categoría filosófico-antropológica de carácter transdisciplinaria.

La contrarrespuesta antihegemónica transdisciplinaria es antropológica y axiológica, pero a condición que se entienda que el alcance del discurso alternativo integra los saberes y difiere del fraccionamiento de la cultura. Se trata de propuestas alternativas teóricometodológicas radicales en el verdadero sentido de la palabra, que atacan el principio de la propiedad tecnológica concentrada, mediante el cual se realiza el control de la transmisión de la información alienadora para beneficio exclusivo del gran capital.

Revista de Ciencias Sociales - Número 67 (2015) - Universidad de Valparáíso - ISSN 0716-7725-Valparaíso, Chile 
El supuesto ideológico falso y excluyente de la producción neutral de conocimiento es desmantelado por la estructura argumentativa del discurso alternativo cuyo gesto desalienador es eminentemente político e ideológico. La información estructurada es producto de la unidad disciplinaria que integra la verdad objetiva con los problemas concretos del ser humano y, por consiguiente, se pone en función de un concepto integral de hombre.

El discurso político de las comunidades indígenas construye su verdad política cuando imbrica la reciprocidad con el concreto simbólico. Esta imbricación es la defensa de la diversidad misma, porque no permite imposición alguna de constructos simbólicos hegemónicos del tecnocratismo neoliberal.

\section{Conclusiones}

El tecnocratismo desconoce los derechos sociales y económicos y, en tal sentido, no reconoce que ellos constituyen una expresión de la representación jurídica socialmente significativa para grandes sectores, incluyendo las propias clases liberales. El conflicto entre el ámbito económico y el político en el tecnocratismo globalizado y neoliberal abandona los principios liberales del período premonopolista ante el empuje del movimiento reivindicador del sujeto excluido, el cual plantea un nacionalismo jurídico-constitucionalista de presupuestos libertarios de orden cosmovisivo colectivista, cuyas bases filosófico-antropológicas, filosófico-políticas y filosófico-jurídicas se encuentran en la imbricación de las conquistas liberales clásicas con el reclamo político soberano y antropológico de las comunidades indígenas.

El sujeto del discurso filosófico-antropológico alternativo le atribuye a la libertad el papel determinante para el orden posible. Este carácter cognitivo está condicionado por la ideología antihegemónica y antitecnocrática de dicho sujeto en el contexto conflictual histórico occidental. El discurso constitucionalista antitecnocrático establece una articulación entre ideología, derechos, epistemología y política para construir el ser de la libertad como un orden ontológico desalienador, a partir del reconocimiento de la praxis comunitaria indígena y sus funciones desalienadoras, y de un conjunto de categorías elaboradas

Facultad de Derecho y Ciencias Sociales - Universidad de Valparaíso - Chile 
por la ciencia antropológica, las cuales son asumidas por las propias comunidades indígenas, entre ellas: diversidad, comunitarismo, reciprocidad, bienestar igualitario, autonomía, derechos colectivos, hombre y naturaleza.

La libertad se debate entre una concepción individualista, y una concepción para la cual el propio individuo y la sociedad constituyen la verdadera esencia. Si prevalece la primera concepción es porque el sujeto parcela la totalidad por algún interés e hiperboliza al individuo. La segunda proviene de un sujeto opuesto que construye un orden ontológico alternativo. El pensamiento alternativo de carácter filosófico, antropológico, jurídico y político insiste en una visión holística de la libertad concreta que favorece su aprehensión totalizadora.

Más allá de cualquier insuficiencia que plantee la resignificación axiológica y epistémica del concepto alternativo de libertad y de constitucionalismo antitecnocrático que le es propio, podría asumirse que posee un orden cosmovisivo colectivista y desalienador frente al concepto de libertad empírico-descriptivo, tecnocrático y hegemónico que sobrevalora el individualismo.

\section{Bibliografía}

ARISTÓTELES: Política, Editado por elaleph.com, (s/p/i). (En soporte digital).

AYÚS REYES, Ramfis: La aventura antropológica. Cultura, poder, economía y lenguaje, Editorial de Ciencias Sociales, La Habana,

Cuba, 2007.

BEA, Emilia: "Teorías de la justicia”. En: Introducción a la teoría del Derecho, Colectivo de autores, Editorial Félix Varela, La Habana, 2006.

BONFIL-SÁNCHEZ, Paloma: "Mujeres indígenas y derechos en el marco de las sociedades multiétnicas y pluriculturales de América Latina”. En: Ra Ximhai, Revista de Sociedad, Cultura y Desarrollo Sustentable, nro. 1, Vol. 8, enero-abril, Universidad Autónoma Indígena de México, El Fuerte, Sinaloa, México, 2012.

COLOMBRES, Adolfo: Teoría transcultural de las artes visuales, Ediciones ICAIC, La Habana, Cuba, 2011.

Revista de Ciencias Sociales - Número 67 (2015) - Universidad de Valparáíso - ISSN 0716-7725-Valparaíso, Chile 
FERNÁNDEZ BULTÉ, Julio: Teoría del Derecho, Editorial Félix Varela, La Habana, 2005.

LUX DE COTÍ, Otilia: Gobernabilidad y pueblos indígenas, Ediciones FLACSO, Costa Rica, 2010.

DÍAZ POLANCO, Héctor: Elogio de la diversidad. Globalización, multiculturalismo y etnofagia, Fondo Editorial Casa de las Américas, La Habana, Cuba, 2008.

DURKEIM, Emile: Las reglas del método sociológico, Editorial A Kal, Madrid, España, 1997.

GEERTZ, Clifford: La interpretación de las culturas, Editorial Gedisa, Barcelona, España, 1992.

GEERTZ, Clifford: Los usos de la diversidad, Editorial Paidós, Barcelona, España, 1996.

—_ Reflexiones antropológicas sobre temas filosóficos, Editorial Paidós, Barcelona, España, 2002.

___ "Descripción densa: hacia una teoría interpretativa de la cultura". En: Bohannan, Paul y Glazer, Mark (compiladores): Antropología. Lecturas, Segunda edición, Editorial Félix Varela, La Habana, Cuba, 2005.

GONZÁLEZ TERREROS, María Isabel: Movimiento indígena y educación intercultural en Ecuador, Ediciones CLACSO,

Universidad Nacional Autónoma de México, México, 2011.

KAWSAY YUYAY, Sumak: Antología del pensamiento indigenista ecuatoriano sobre Sumak Kawsay, Centro de Investigaciones en Migraciones (CIM), Universidad de Huelva, España, 2014.

KROEBER, Alfred Louis: "El concepto de cultura en la ciencia". En: Bohannan, Paul y Glazer, Mark (compiladores): Antropología. Lecturas, Segunda edición, Editorial Félix Varela, La Habana, Cuba, 2005.

LORENTE FERNÁNDEZ, David: "La transmisión intergeneracional del conocimiento mítico a través de la tradición oral: los ahuaques o espíritus del agua en la Sierra de Texcoco, México”. En: Vera, Ana y Robichaux, David (compiladores): Familias y culturas en el espacio latinoamericano, Universidad Iberoamericana-Centro de Investigación y Desarrollo de la Cultura Cubana Juan Marinello, México, 2008.

Facultad de Derecho y Ciencias Sociales - Universidad de Valparaíso - Chile 
MAUSS, Marcel: "Ensayo sobre los dones. Motivo y forma de cambio en las sociedades primitivas". En: Sociología y antropología, Editorial Tecnos, Madrid, España, 1971.

MARÍA MARDONES, José: ¿Qué es la posmodernidad? En: "Cuadernos de Orientación Familiar", Alianza Universidad, Madrid (s/f).

PAPACCHINI, Angelo: Filosofía y derechos humanos, Universidad del Valle, Cali, 1994.

STUART MILL, John: Sobre la libertad, Universidad Autónoma de Centro América, Costa Rica, 1965.

HURTADO, Román y ALFONSO, Justino: Aprehensión identitaria: la cultura y sus mediaciones, caso Bolivia, Tesis presentada en opción

al grado científico de Doctor en Ciencias Filosóficas, Editorial Universitaria, Ministerio de Educación Superior, Universidad de La Habana, Cuba, 2008.

ROUSSEAU, Juan Jacobo: El contrato social, Editorial Taums, Madrid, 1966.

STEWARD, Julian: "Niveles de integración sociocultural: un concepto operativo". En: Southwestern Journal of Anthropology, nro. VII, 1951.

TEREUCÁN, Julio: Redes de reciprocidad e intercambio y su influencia en la cultura y economía de una comunidad postnahua de México.

Tesis de Maestría, Universidad Iberoamericana de México, México, 2003.

__ Caro Puentes, Aracely y Lucy Ketterer: "La reciprocidad como mecanismo de control social en los contextos familiares indígenas: los mapuches del sur de Chile". En: Vera, Ana y Robichaux, David (compiladores): Familias y culturas en el espacio latinoamericano, Universidad Iberoamericana-Centro de Investigación y Desarrollo de la Cultura Cubana Juan Marinello, México, 2008.

TYLOR, Edward B.: "Cultura Primitiva". En: Bohannan, Paul y Glazer, Mark (compiladores): Antropología. Lecturas, Segunda edición, Editorial Félix Varela, La Habana, Cuba, 2005.

VARGAS HERNÁNDEZ, José Guadalupe: “Movimientos sociales para el reconocimiento de los movimientos indígenas y la ecología política indígena”. En: Ra-Ximhai, Revista de Sociedad, Cultura y Desarrollo Sustentable, No 3, Vol.1, septiembre-diciembre Universidad Autónoma Indígena de México, El Fuerte, Sinaloa, México, 2005. 


\section{Documentales}

Acta de Reconstitución de la Nación Aymara-Qhichwa. Manifiesto de Jach'ak'achi, Bolivia, 2001. Disponible en www.puebloindio.org/ Actualidades/ [Consultado 20 de junio de 2014].

Congreso Nacional Indígena. El Movimiento Nacional Indígena, México, 1997. Disponible en www.laneta.apc.org/cni/mhmni.htm [Consultado 20 de junio de 2014].

Declaración de Quito, Ecuador, 1990. Disponible en www.nativeweb. org/papers/statements/quincentennial/quito.php [Consultado 20 de junio de 2014].

Estatuto, Consejo Indio de Sud América (CISA), 1998. Disponible en www.puebloindio.org [20 de junio de 2014].

Políticas de las FAO sobre pueblos indígenas y tribales, 2011. Disponible en www.fao.org/docrep/013/ i1857s/i1857s.pdf [Consultado 20 de junio de 2014]. 